\title{
Innovative Inventory Pooling System Based on Computing and Optimization Techniques
}

\author{
Lilawadi Phatanarajata, Sukree Sinthupinyo, Achara Chandrachai, and Thira Chavarnakul
}

\begin{abstract}
Monte Carlo Simulation method is a famous and well known technique, which can be effectively used to solve inventory management problems in many industries. Thus, this study combines not only computing but also optimization techniques to provide the most optimal solution for solving inventory problems of sport retailers in Thailand. The purpose of this study is to determine the optimal system service fee for Innovative Inventory Pooling System (IIPS) by maximizing the increment of system service income and total profit. The simulation model has represented the inventory levels of sports retailers comparing between the traditional models and pooling model. Employing Monte Carlo Simulation (MCS), the simulation model establishes the opportunity for reducing cost of lost sales, and creating the profit and system service income. Therefore, three specific factors are discussed in this study. A simple equation to find the optimal system service fee for IIPS is definitely developed. Finally, the result will be presented to demonstrate the maximized system service fee and it will also use the results obtained for designing and developing the system in order to help create the maximum sustainable usability in the future.
\end{abstract}

Index Terms-Monte Carlo Simulation, optimization technique, inventory management, inventory pooling.

\section{INTRODUCTION}

Monte Carlo is a computing algorithm using the random numbers or variables with the invariably uniform distributions. The working method of this technique is to randomize the variables and then include them into the results of the searched data in order to randomize them into the new probability [1], [2].

Monte Carlo technique is a method which is used to stimulate business problems in today's business scenario [3], such as competitive advantage and sales opportunity since understanding the current problems is typically crucial to handle the business successfully. Oftentimes, only a few small factors may cause a major impact, which forces the business to discontinue. Therefore, each company needs to identify the factors that lead to its success and failure and to adapt its strategy for both profitability and sustainability [4]. Applying Monte Carlo technique to simulate the buying and selling process as well as the inventory management process

Manuscript received August 24, 2018; revised March 18, 2019.

L. Phatanarajata is with the School of Technopreneurship and Innovation Management, Chulalongkorn University, 254 Phayathai Rd., Phatumwan Bangkok, 10330 Thailand (e-mail: lilawadi.ph@student.chula.ac.th).

S. Sinthupinyo is with the Department of Computer Engineering, Chulalongkorn University, 254 Phayathai Rd., Phatumwan Bangkok, 10330 Thailand (e-mail: sukree.s@ chula.ac.th).

A. Chandrachai and T. Chavarnakul are with the Faculty of Commerce and Accountancy, Chulalongkorn University, 254 Phayathai Rd., Phatumwan Bangkok, 10330 Thailand (e-mail: achandrachai@gmail.com, thira@cbs.chula.ac.th). is a key factor and also a popular way of addressing the customer needs. However, responding to customer requirements may not be good enough to keep on the organization from surviving owing to higher operating costs from current economic conditions [5]. Therefore, it is necessary for the vendor/service provider to manage the return and income sufficiently and appropriately. Introducing engineering techniques and information technology to this field is one of the key strategies to help organizations survive since the optimization technique is the method using various data or variables to conduct decisions under certain conditions [6], [7]. For an example of the case study, the airline business needs to optimize the design of employees' flight schedules as well as the break-even point for flights [8]. These data are derived from the customer demand model to simulate the situation using the Monte Carlo technique, by which the probability of the model is derived from the clustered and classified data.

For the above reason, this research uses the Monte Carlo technique in computing to create an Innovative Inventory Pooling System (IIPS) for forecasting sales, performing the estimation of profits and reducing the opportunity cost of lost sales by learning from customer data, store data, and inventory information (as the input information) and applying linear programming methods, which is a technique for optimizing the system service fees for system users by establishing equation's optimization. Combining computing techniques for the IIPS simulation and Optimization technique can provide the optimal solution and can be another option for businesses to operate a sustainable survival in the business unit.

\section{Methodology}

For enabling the understanding of the operation process of wholesaler and retailer for sports equipment in Thailand, the analysis of the operating system is need. This study will help to specify problems and allocate some points that can be additionally improved. According to the observation and data collection from the sports equipment wholesalers and retailers in Thailand, the majority of retailer companies in Thailand often operate the business by using a traditional model. The principal activities of the stores including placing product orders, receiving product orders, selling products and exchanging products with their trading partners are performed, so the operation will mainly lack a transparent system, which could result in many mistakes since the operation process is also primarily based on the assumption of placing product orders from wholesalers.

The product orders will be placed on a daily basis that results in the product demands to fluctuate on a regular basis. 
Additionally, the format of inventory management to prevent the stock out performance has resulted in some products with the higher value when the business has faced with problems. Some models and sizes of the product also do not match the demand of the group of the customer in the specific store. This incident then will result in the product dead stock.

Based on the problems on the traditional model of inventory management, the researcher has created a simulation model to compare the profit $\&$ the opportunity cost of lost sale that may occur from the conventional model of the inventory management in the single store. Moreover, the researcher will also compare it with the store that has been applied with the IIPS. However, the use of the IIPS to implement in the replacement of the traditional method resulting in the participated stores will be charged of additional expenses including the system service fee. The system needs to acquire the maximum of system service income to be able to continuously and sustainably manage, monitor, and develop the system.

Thus, it is necessary for this research to enable to explore how to acquire the optimization of system service fee so that it will have the highest value on the investment. When the IIPS system has been applied, the revenue of each store should naturally increase after the system operation improvement. Hence, the profit needs to increase while the opportunity cost of the lost sale needs to decrease after the system improvement. This will help to attract stores to join the IIPS.

From Table I, it displays the comparison from changes that occur after the store improvement by applying the IIPS.

TABLE I: COMPARISON FACTORS OCCUR BETWEEN TRADITIONAL MODEL AND THE IIPS MODEL

\begin{tabular}{lll}
\multicolumn{2}{c}{ AND THE IIPS MODEL } & \\
\hline \hline Factors & $\begin{array}{l}\text { Traditional } \\
\text { Model }\end{array}$ & $\begin{array}{l}\text { After applied } \\
\text { the IIPS Model }\end{array}$ \\
\hline Profit $(\%)$ & + & ++ \\
Opportunity of lost sale $(\%)$ & -- & - \\
Inventory (Qty) & ++ & + \\
System service fee $(\%)$ & $\mathrm{x}$ & + \\
\hline \hline
\end{tabular}

Table I displays the comparison between before and after store improvement, which is describe as follow:

\section{A. Profit and Lost Sale}

After initiating the application of IIPS system, the stores will have more opportunities to sell their products as the profit \& loss sales rate is decreasing. The reason for the reduction in the profit $\&$ loss sales is that the stocks within the IIPS system have higher quantities than the inventory of each separate store. It will result in the ability of each store to be able to respond to more customers' need, which will lead to a higher total income in the system.

\section{B. Inventory Level}

After the application of IIPS system has been processed, it will result in the reduction of the actual quantity for the inventory for each store. The use of inventory pooling system will help reduce the necessity in placing a product order, and it can be shifted to stock within the IIPS system instead. Stores in the system will increase the opportunities for selling their more products. This incident will help reduce the quantity of the product in the inventory and minimize overstock problems.

\section{System Service Fee}

The system service fee will automatically increase when compared with the tradition inventory management model as it will function as an expense for the IIPS. Thus, the researcher will need to evaluate and analyze for the most appropriate fee for the system service fee. This will assist in both IIPS management and stores to both receive the highest benefits.

From the primary analysis, it can evaluate that the application of the IIPS for inventory management will be able to create benefits for stores. The process illustrates how IIPS system can benefit for the participated stores and how IIPS system will provide the ultimate benefits. It will be displayed in Fig. 1, which is the chart displaying the hypothesis procedure.

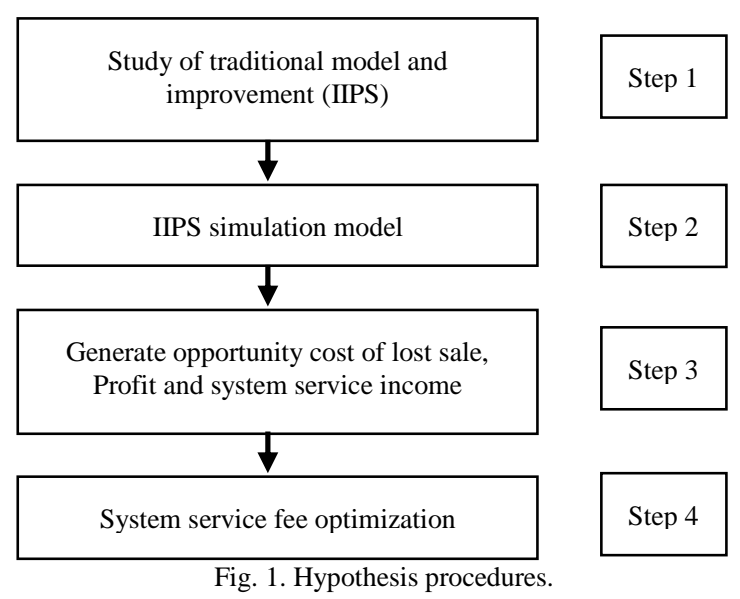

Step 1: The study of the current model and improvement

From the data collection in the sampling stores, it was found that there were 103 products in each store but the size and quantities of each model in each store are significantly different. This shows that the demand for each store and the needs of each customer are different.

The researcher obliged to ascertain the constituents that directly influence on the demands of the customer, and then the researcher accumulated the customer data from customers who participated in buying in each store as 100 samples per store in 3 stores, accounting for 300 data samples in total. Sample data collected include gender, age, occupation, brand, product's model, product's newness, color, and customer's location.

The data obtained from the questionnaire were highly distributed, lacking in characteristics and factors determining the purchase decision of the customers. The researcher selected the variables to analyze the characteristics and interests of customers instead of using customer demand data to find the appropriate inventory data. Then, the researchers used the Forward Selection Method (FRA), using weighting method from Classification model type via the Rapid Minor program, which separates the data and performs the performance measurement of the group of additive equations for one by one, and applied the Cross Validation model to select the groups of variables that can result in the highest accuracy of the equation [9], [10]. The results showed that the variables selected by the Forward Selection technique which is suitable for the equation when consisted of 3 variables as follows: 
- Product' s model (Model class)

- Product's newness

- Customer's location

From the study of the data collection, it was found that the sports equipment is considered as a fashionable product, which has a short life cycle. Based on the observation of customers entering the store to purchase the product, the majority of customers more than $50 \%$ will have a possibility to not receive their desired products. This is because their desired products are not available in the store or another meaning; the specific store does not provide products that match the customer's needs. This is displayed in Fig. 2, which exhibits the customer flow when the customers visit the stores.

\section{Traditional Model}

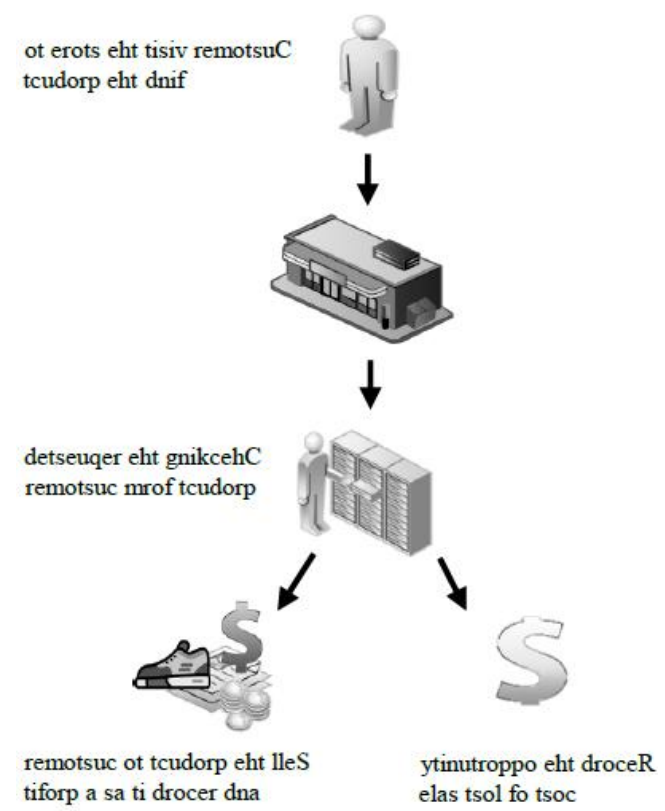

Fig. 2. Customer flow to the individual store.

From the primary analysis of the problem, it was found that the main reason that stores were unable to close the sales because they lack the products matching with customers' need. Besides this, another important reason is that they fail to predict the needs of the customer [11], [12]. Regarding the problems in an inadequate inventory space of the stores, the store refuses to stock certain products and only chose to select specific models because the stores faced with high expenses for the inventory management.

The researcher has considered regarding the problem of reducing expenses for store inventory management and increase the capability in selling the products that can mainly find out the exact customer's needs since the stores can also add the product to the IIPS, and the system will charge the system service fee. The system service fee will be calculated once the buy-sell occurs. This progress has been applying to use as shown in Fig. 3.

From the Fig. 3 displaying customer flow, it shows that the stores increase the opportunity of selling their products. This is because the quantity of the inventory increases and has more variations (IIPS system). It helps to serve more to the customers' needs and thus help increase the service level. It also helps to increase profit and reduce the opportunity cost of lost sale.

Based on the statement mentioned, if we would like to increase the system service income for the use of system management. The stores within the system will need to pay the system service fee for the system operation.

However, if the system has specified system service fee that is too high, the price of the product within the IIPS will also increase. This may result in the stores to decide not to use the IIPS so they can purchase products and sell it to their customers by themselves.

The objective of this research is to optimize the system service income so the system will receive the highest system service income and will not reduce the benefits of each store that participated in the system. This shows that the IIPS is essential to minimize opportunity cost of lost sale for each participated stores. Thus, if the rate of opportunity cost of lost sale is reduced, it will show that the system can respond to the needs of the store and the system service income will increase.

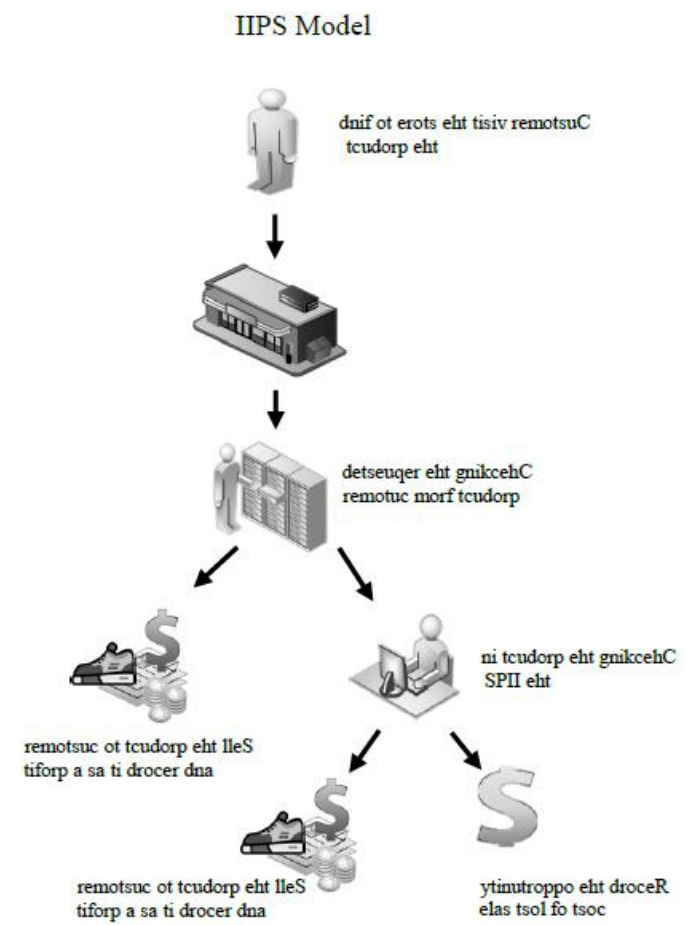

Fig. 3. Customer flow to the store when using IIPS system.

\section{Step 2: The IIPS simulation}

The data received from the data collection of the inventory management, customers' database, and product demand database for three stores will use to create a simulation model. An example of partial data for the three stores is shown below in Table II, III and IV.

TABLE II: PERCENTAGES OF MOdel Class's DEMAND

\begin{tabular}{lrrr}
\hline \hline Class & $\begin{array}{r}\text { Model Class } \\
\text { Store A }\end{array}$ & $\begin{array}{r}\text { Model Class } \\
\text { Store B }\end{array}$ & $\begin{array}{r}\text { Model Class } \\
\text { Store C }\end{array}$ \\
\hline Top & $81 \%$ & $68 \%$ & $32 \%$ \\
Middle & $14 \%$ & $21 \%$ & $51 \%$ \\
Basic & $5 \%$ & $11 \%$ & $17 \%$ \\
\hline \hline
\end{tabular}

TABLE III: PERCENTAGES OF PRODUCT'S NEWNESS DEMAND

\begin{tabular}{lrrr}
\hline \hline \multirow{2}{*}{ Newness } & $\begin{array}{r}\text { Newness } \\
\text { Store A }\end{array}$ & $\begin{array}{r}\text { Newness } \\
\text { Store B }\end{array}$ & $\begin{array}{r}\text { Newness } \\
\text { Store C }\end{array}$ \\
\hline New & $57 \%$ & $71 \%$ & $85 \%$ \\
Colorway & $23 \%$ & $14 \%$ & $15 \%$ \\
Old & $20 \%$ & $15 \%$ & $0 \%$ \\
\hline \hline
\end{tabular}


Computing the opportunity cost of lost sales, profit and optimal system service requires to configure the random variables of customer's perferances in the simulation in order to simulate the situation when customers come to the store and investigate the avalibility of inventory in the targeted store to match the customer demand. Therefore, random variables were generated from the cumulative probability and uses the RAND () command in Microsoft $®$ Excel program. This can be explained as shown in Fig. 4.

TABLE IV: PERCENTAGES OF PRODUCT's SIZE DEMAND

\begin{tabular}{|c|c|c|c|c|c|}
\hline Size & $\begin{array}{l}\text { Product's } \\
\text { Store A }\end{array}$ & size & $\begin{array}{l}\text { Product's } \\
\text { Store B }\end{array}$ & size & $\begin{array}{l}\text { Product's size } \\
\text { Store C }\end{array}$ \\
\hline 060 & & $1 \%$ & & $0 \%$ & $3 \%$ \\
\hline 065 & & $3 \%$ & & $3 \%$ & $16 \%$ \\
\hline 070 & & $8 \%$ & & $4 \%$ & $16 \%$ \\
\hline 075 & & $14 \%$ & & $11 \%$ & $17 \%$ \\
\hline 080 & & $25 \%$ & & $20 \%$ & $11 \%$ \\
\hline 085 & & $18 \%$ & & $19 \%$ & $14 \%$ \\
\hline 090 & & $12 \%$ & & $16 \%$ & $14 \%$ \\
\hline 095 & & $8 \%$ & & $11 \%$ & $6 \%$ \\
\hline 100 & & $5 \%$ & & $12 \%$ & $2 \%$ \\
\hline 105 & & $6 \%$ & & $3 \%$ & $0 \%$ \\
\hline 110 & & $0 \%$ & & $1 \%$ & $1 \%$ \\
\hline
\end{tabular}

The simulation aims to find the opportunity cost of lost sale and profit from each system service fee. It will create a mock-up of each percentage from the system service fee in 30 test rounds. The result will be calculated with the mean by using percentage of system service fee from $1 \%$ until $25 \%$.

\section{Step 3: Result values}

From the simulation of traditional model that uses the real database from sample stores, it found that the net profit was 136,916 THB and the opportunity cost of lost sale was $1,006,965$ THB or equivalent to $67 \%$. After applying the IIPS, it will display the result shown in Table $\mathrm{V}$ as follow:

\section{TABLE V: RESULTS FROM THE IIPS SIMULATION}

\begin{tabular}{|c|c|c|c|c|}
\hline $\begin{array}{l}\text { System } \\
\text { service } \\
\text { fee }(\%)\end{array}$ & $\begin{array}{l}\text { System } \\
\text { service } \\
\text { income } \\
(\mathrm{THB})\end{array}$ & $\begin{array}{c}\text { Opportunity } \\
\text { cost of lost } \\
\text { sale of IIPS } \\
\text { Model (THB) }\end{array}$ & $\begin{array}{l}\text { Opportunity } \\
\text { cost of lost } \\
\text { sale of IIPS } \\
\text { Model (\%) }\end{array}$ & $\begin{array}{l}\text { Net Profit } \\
\text { of stores } \\
\text { applied } \\
\text { IIPS Model } \\
\text { (THB) }\end{array}$ \\
\hline $1 \%$ & - & 685,738 & $46 \%$ & 183,058 \\
\hline $2 \%$ & 2,427 & 720,506 & $49 \%$ & 176,331 \\
\hline $3 \%$ & 4,895 & 720,678 & $49 \%$ & 176,560 \\
\hline $4 \%$ & 9,140 & 726,754 & $50 \%$ & 169,476 \\
\hline $5 \%$ & 11,602 & 718,084 & $49 \%$ & 168,534 \\
\hline $6 \%$ & 14,525 & 724,336 & $49 \%$ & 166,877 \\
\hline $7 \%$ & 15,683 & 729,602 & $50 \%$ & 164,696 \\
\hline $8 \%$ & 16,882 & 743,403 & $51 \%$ & 161,341 \\
\hline $9 \%$ & 19,776 & 737,453 & $50 \%$ & 158,465 \\
\hline $10 \%$ & 21,094 & 752,112 & $51 \%$ & 152,405 \\
\hline $11 \%$ & 23,238 & 762,582 & $52 \%$ & 153,034 \\
\hline $12 \%$ & 23,020 & 788,643 & $53 \%$ & 150,852 \\
\hline $13 \%$ & 22,815 & 792,052 & $54 \%$ & 152,175 \\
\hline $14 \%$ & 19,428 & 826,083 & $56 \%$ & 151,417 \\
\hline $15 \%$ & 19,046 & 847,314 & $57 \%$ & 145,406 \\
\hline $16 \%$ & 18,753 & 870,622 & $59 \%$ & 143,840 \\
\hline $17 \%$ & 18,026 & 860,714 & $58 \%$ & 146,946 \\
\hline $18 \%$ & 12,835 & 918,872 & $62 \%$ & 143,385 \\
\hline $19 \%$ & 12,256 & 903,770 & $61 \%$ & 149,264 \\
\hline $20 \%$ & 12,011 & 916,962 & $62 \%$ & 143,576 \\
\hline $21 \%$ & 12,236 & 921,700 & $62 \%$ & 142,804 \\
\hline $22 \%$ & 10,851 & 949,264 & $63 \%$ & 142,237 \\
\hline $23 \%$ & 8,955 & 926,148 & $63 \%$ & 146,469 \\
\hline $24 \%$ & 7,302 & 960,825 & $65 \%$ & 140,945 \\
\hline $25 \%$ & 4,631 & 979,275 & $65 \%$ & 138,493 \\
\hline
\end{tabular}

According to Table $\mathrm{V}$, it found that the profit and the opportunity cost of lost sale generally decrease when using the IIPS during the period of system service fee from 1 to $25 \%$ and the total profit for all stores increase after the use of the IIPS.

The total results will be collected from the simulation and calculated for the repetition structure for the appropriate simulation. It will then be tested for the reliability of the model by using the Normal Distribution experiment of system service fee, profit, opportunity cost of lost sales (times). It aims to find the characteristic of the distribution whether it is a normal distribution or not. This experiment will be complete through the Minitab program.

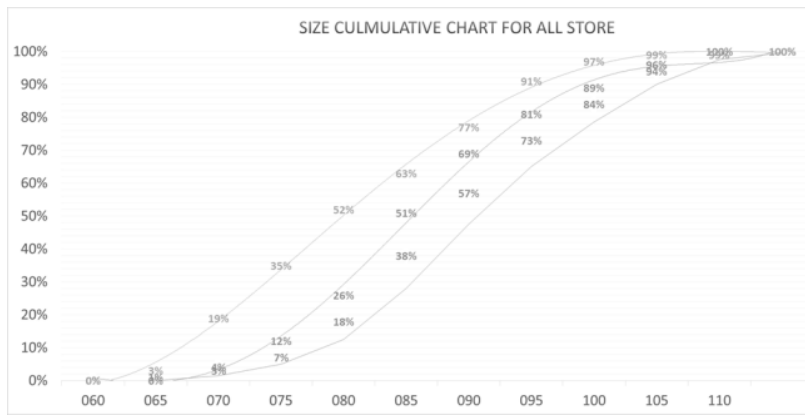

Fig. 4. Examples cumulative chart for product's size in all sample stores.

According to the initial experiment of the data distribution for the total of 30 test rounds, it found that the reliability is at $95 \%$. The data used in the research will help determine where the distribution is a normal distribution or not and will be base on the hypothesis of the experiment as follow:

$\mathrm{H}_{0}$ : refers to Normal Distribution

(Normal Distribution)

$\mathrm{H}_{1}$ : refers to Non-Normal Distribution

(Non-Normal Distribution)

Fig. 5, Fig. 6, and Fig. 7 display the hypothesis results of system service income (THB), opportunity cost of lost sale, and net profit when the percentage of system service fee is $11 \%$.

According to the SPSS normality test for the 30 test rounds, it gives indication that the reliability is at $95 \%$. This can be concluded that the three types of information such as system service fee (THB), profit (THB), and opportunity cost of lost sale (times) possess normal distribution as the value of $\mathrm{P}-$ Value is more than 0.05 .

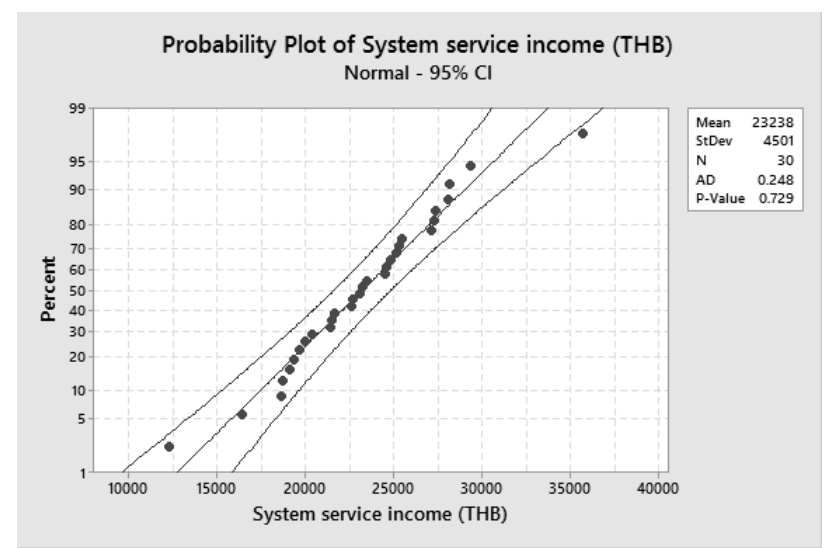

Fig. 5. Diagram of hypothesis testing of system service income at system service fee at $11 \%$.

After engaging in the SPSS normality test, the result is that 
there is a normal distribution where it is possible to engage in the Repetition structure to use the results and compare with (1).

$$
N=\left(\frac{z \times s}{d}\right)^{2}
$$

$Z=$ Reliability at $95 \%$

$\left(Z_{0.025}\right.$ is equivalent to critical values of 1.96)

$S=$ Standard deviation

$d=0.05 \times$ average total cost (Deviation)

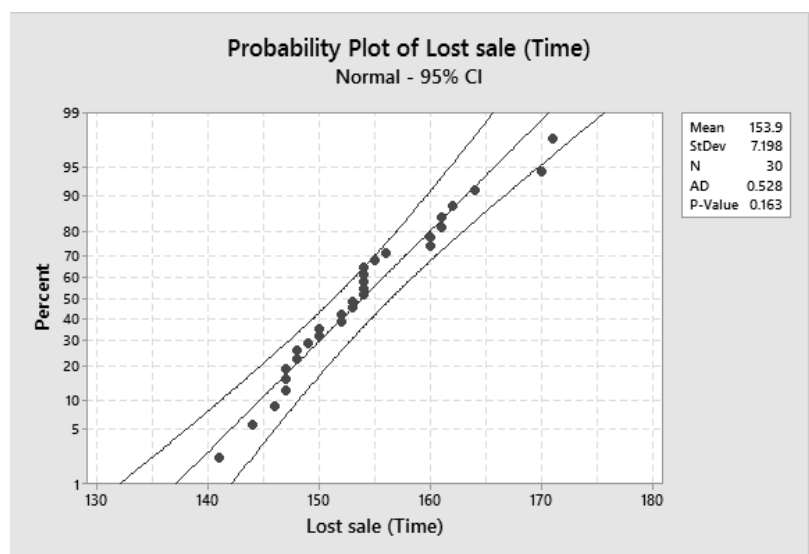

Fig. 6. Diagram of hypothesis testing of opportunity cost of lost sale at system service fee at $11 \%$.

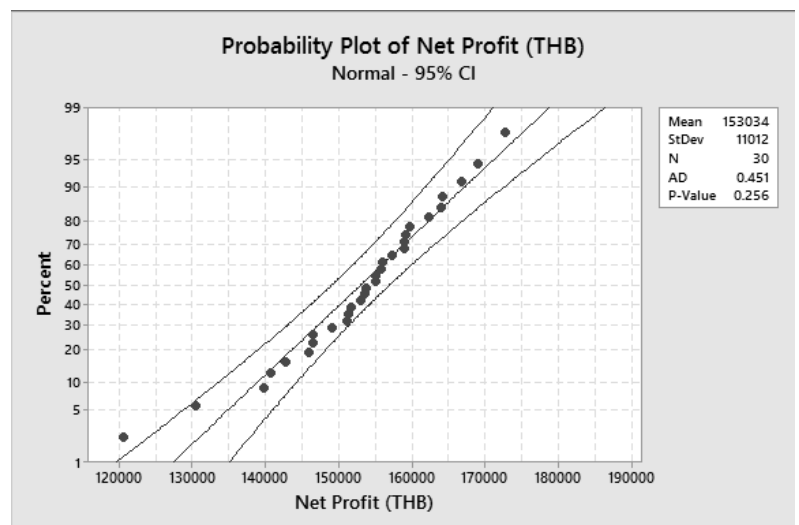

Fig. 7. Diagram of hypothesis testing of net profit at system service fee at $11 \%$.

After combining the system service fee, profit, and opportunity cost of lost sale from 30 test rounds, it can be substituted for the equation and will be equal to:

TABLE VI: RESULTS OF DATA REPETITION STRUCTURE

\begin{tabular}{lllll}
\hline \hline & $z$ & $s$ & $d$ & $N$ \\
\hline System service fee & 1.96 & 2027.578 & 19046.29 & 17.41 \\
Profit & 1.96 & 12359.49 & 145406 & 11.10 \\
Opportunity of lost sale & 1.96 & 8.281054 & 169.9 & 3.65 \\
\hline \hline
\end{tabular}

From Table VI, it can be concluded that the result of the new Repetition Structure N from the (1), shows in the smaller amount of Repetition structure than the Repetition structure in the preliminary simulation in the first 30 test rounds of the simulation.

\section{Step 4: System service fee Optimization}

From the result of the overall IIPS simulation, it will then calculated to find the maximum percentage of system service fee which will result in the system service income to have the highest value as shown in the equation

$$
Z=\frac{\sum_{k=1}^{N}\left\lfloor\sum_{j=1}^{n}\left(P_{j}+T_{j}\right) \times A_{i}\right\rfloor}{30}
$$

The total equation from the system service income for each system service fee $(i)$ will be calculated only in the case that each store can sell the products. The condition of the system in closing the sales is when the stores participating in the IIPS will need to receive profit from selling the products. It will calculate into the equation as followed:

$$
R_{j} \geq\left(P_{j}+T_{j}\right) \times\left[\left(P_{j}+T_{j}\right) \times A_{i}\right]
$$

After the equation is calculated, the equation will produce linear equation as followed:

$$
\begin{gathered}
\text { Maximize } \quad Z=\frac{\sum_{k=1}^{N}\left\lfloor\sum_{j=1}^{n}\left(P_{j}+T_{j}\right) \times A_{i}\right\rfloor}{30} \\
R_{j} \geq\left(P_{j}+T_{j}\right) \times\left[\left(P_{j}+T_{j}\right) \times A_{i}\right]
\end{gathered}
$$

The following notation and assumptions are used in this study:

$i$ the order of system service fee's percentage starts at 1 ,increased by 1 to 25

$j$ the customer's order starts with the $1^{\text {st }}$ customer to $300^{\text {th }}$ customer

$k$ the repetition starts at $1^{\text {st }}$ round to $30^{\text {th }}$ round

$Z$ the system service income (THB)

$T_{j}$ the transportation cost (THB)

$A_{i}$ the system service fee's percentage

$P_{j}$ the pooling cost (THB)

$R_{j}$ the retail price (THB)

\section{RESULTS}

From Fig. 8, after replacing with (2), it needs to follow the condition of the (3), the information will be used to plot the graph by specifying $\mathrm{X}$-axis to be percentage of system service fee in the different level. Y-axis will represent System service income as shown in Fig. 8.

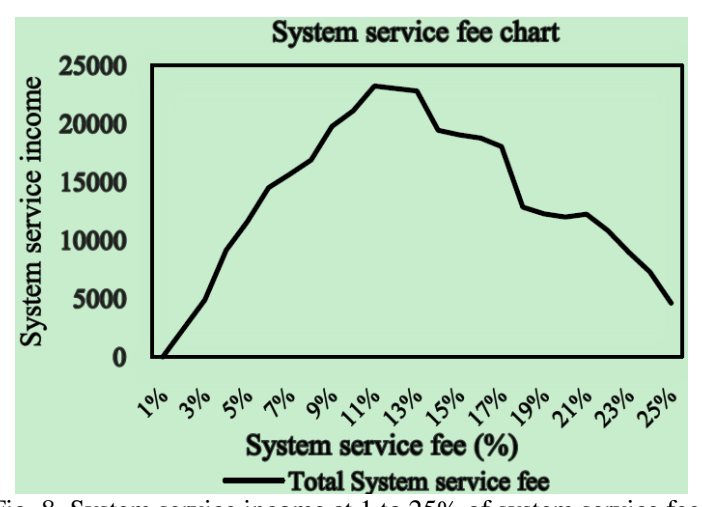

Fig. 8. System service income at 1 to $25 \%$ of system service fee.

From using the data to plot the graph, it is shown that the percentage of system service fee of the IIPS will reach the maximum of system service income at $11 \%$. The store profit 
before and after the use of the IIPS will increase from initially at $136,916 \mathrm{THB}$ to $153,034 \mathrm{THB}$ or equivalent to $11.77 \% .15 \%$ will reduce the opportunity cost of lost sale from $67 \%$ to $52 \%$.

\section{CONCLUSION AND RECOMMENDATION}

From the result of the simulation and substitution of the equation to find the optimization value for the percentage of system service fee and under these conditions, the stores that participated in the IIPS will need to receive profit each time when they use the system (If the stores did not earn any profit, the stores will reject customers' order and result in opportunity cost of lost sale), the system service fee will be equivalent to $11 \%$. The profit of the store before and after the use of the IIPS will increase from initially at 136,916 THB to $153,034 \mathrm{THB}$, which is equal to $11.77 \%$. The opportunity cost of lost sales also will reduce by $15 \%$ from $67 \%$ to $52 \%$.

It can conclude that for each store to input their products in the IIPS; it will be able to help reduce the opportunity cost of lost sale and increase the profit for each store. The system will also be profitable by using the optimization techniques.

Regarding the future research, it should add broader sample groups as this research only study three stores that have a significant difference in location, products, and customers' need, as well as shelf products. This is to enable the understanding of the problems and characteristics of each store. Additionally, it is still unable to find any other pattern in the sample group within this research. The research can also be further study in other related business sectors that use the similar management approach in the inventory management. It should even compare with other industries to comprehend the differences in each sector, which will be able to help develop the system to match the needs. It will also assist to estimate the income more accurately.

There should be a continuous study and research on different factors to understand the change and capability in the improvement of the work operation to be up to date and highly effective. The future research should also focus on the inventory management as well as the cost of the product in other inventories. The next research should also focus on the analysis regarding the inventory pooling system approach to reduce other costs for inventory management. Besides, this research also only focuses on three different stores; thus, the specification for system service fee in the constant pattern may not be the best solution in case that the system has the large number of stores that join the IIPS. The indication for the percentage of system service fee for progression rates may be more suitable and fair for the stores.

\section{REFERENCES}

[1] D. Walters, "Applying the monte carlo simulation," Retail and Distribution Management, vol. 3, no. 1, pp. 50-54, 1975.

[2] A. A. Juan, J. Faulin, S. E. Grasman, M. Rabe, and G. Figueira, "A review of simheuristics: Extending metaheuristics to deal with stochastic combinatorial optimization problems," Operations Research Perspectives, vol. 2, pp. 62-72, Mar. 2015.

[3] A. Prakash, S. K. Jha, and R. P. Mohanty, "Scenario planning for service quality: a Monte Carlo simulation study," Journal of Strategy and Management, vol. 5, no. 3, pp. 331-352, 2012.

[4] S. Kumar and C. Chandra, "Managing multi-item common vendor inventory system with random demands," International Journal of
Physical Distribution \& Logistics Management, vol. 32, no. 3, pp. 188-202, 2002.

[5] M. Cooper, "Cost and delivery time implications of freight consolidation and warehousing strategies," International Journal of Physical Distribution \& Materials Management, vol. 14, no. 6, pp. 47-67, 1984.

[6] K. Katsaliaki and N. Mustafee, "Improving decision making in healthcare services through the use of existing simulation modelling tools and new technologies," Transforming Government: People, Process and Policy, vol. 4, no. 2, pp. 158-171, 2010.

[7] R. Banomyong and A. Sopadang, "Using Monte Carlo simulation to refine emergency logistics response models: A case study," International Journal of Physical Distribution \& Logistics Management, vol. 40, no. 8, pp. 709-721, 2010.

[8] A. S. Karaman, "Simulating air transportation networks under capacity constraints: Transforming into a multi-hub infrastructure," Kybernetes, vol. 47, no. 6, pp. 1122-1137, 2018.

[9] B. G. Tabachnick and L. S. Fidell, Using Multivariate Statistics, 5th ed Boston, MA.: Allyn \& Bacon Pearson Education, 2007.

[10] G. Def and B. S. Everitt, A Handbook of Statistical Analyses using SAS, 2th ed. Boca Raton, Florida: Chapman \& Hall CRC, 2002.

[11] L. Trapani and G. Urga, "Optimal forecasting with heterogeneous panels: A Monte Carlo study," International Journal of Forecasting, vol. 25 , no. 3, pp. 567-586, 2009.

[12] S. Alvisi and M. Franchini, "Assessment of the predictive uncertainty within the framework of water demand forecasting by using the model conditional processor," Procedia Engineering, vol. 89, no. 2014, pp. 893-900, 2014.

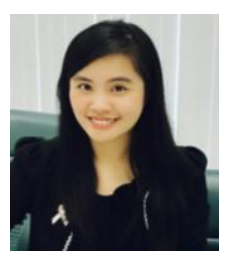

Lilawadi Phatanarajata was born in Bangkok, Thailand, September 1986; She is a PhD student in technopreneurship and innovation management program from Chulalongkorn university, thailand. she holds a bachelor degree in information communication and technology from Mahidol Universitiy, Thailand and she also holds a master degree in design and branding strategies from Brunel University at London, UK. Her research interests include innovation, inventory management, inventory pooling, collaboration, cooperation, and adoption.

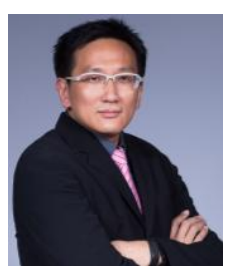

Sukree Sinthupinyo holds a bachelor degree, a master degree and $\mathrm{Ph} . \mathrm{D}$. in computer engineering from Chulalongkorn University, Thailand. Currently he is working as a lecturer and he has been an assistant professor doctor in the Department of Computer Engineering, Chulalongkorn University. His research areas are artificial intelligence, machine learning \& pattern recognition, engineering.

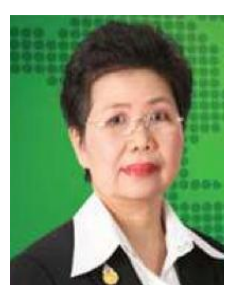

Achara Chandrachai holds a bachelor degree of commerce and accountancy from Chulalongkorn University, Master of Business Administration (2nd honor roll) from National Institute of Development Administration, Ph.D. in quantitative business analysis from Arizona State University. She has been a professor emeritus of Technopreneurship \& Innovation Management Program since 2006 and manager of IMET (Institute of Management Education Thailand) since 2008. Her research interests are technology commercialization, business, industry analysis and strategies, business innovation.

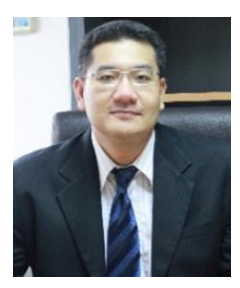

Thira Chavarnakul received his B.E. in civil engineering from Chulalongkorn University, Thailand; got his M.B.A. from Chulalongkorn University, Bangkok, Thailand; got his M.Sc. and Ph.D. in engineering management from Missouri University of Science and Technology, USA. He is currently an assistant professor and head of the Department of Commerce at the Faculty of Commerce and Accountancy. 